This item was submitted to Loughborough's Institutional Repository (https://dspace.lboro.ac.uk/) by the author and is made available under the following Creative Commons Licence conditions.

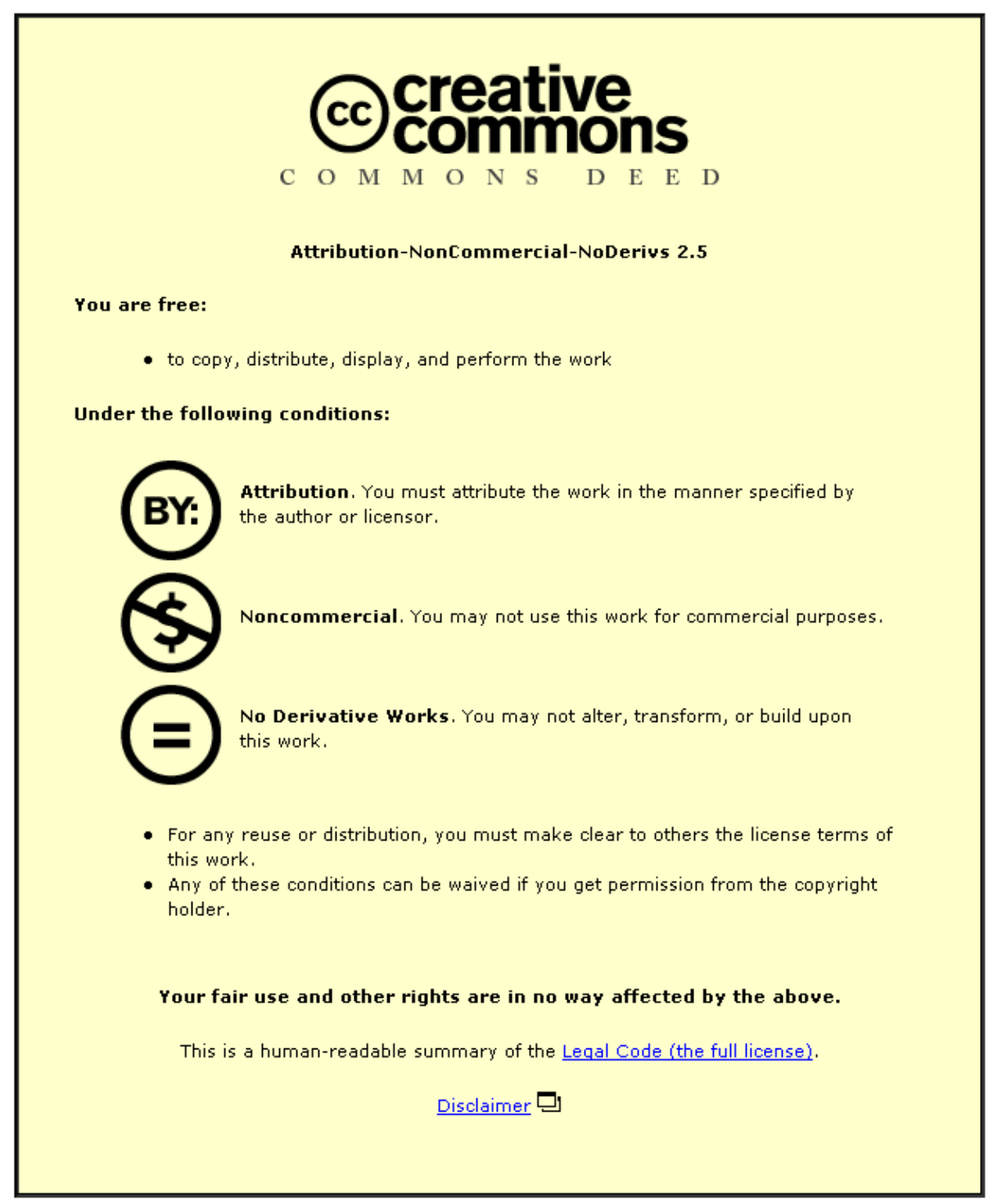

For the full text of this licence, please go to: http://creativecommons.org/licenses/by-nc-nd/2.5/ 


\title{
Implications of the End-of-Life Vehicles Directive on the vehicle recovery sector
}

\author{
C Edwards*, G Coates, P G Leaney, and S Rahimifard \\ Wolfson School of Mechanical and Manufacturing Engineering, Loughborough University, Loughborough, UK
}

The manuscript was received on 27 September 2005 and was accepted after revision for publication on 14 March 2006.

DOI: $10.1243 / 09544054 J E M 473 S C$

\begin{abstract}
To cope with the environmental effects of 9 million tonnes of vehicles that reach the end of their useful lives each year in Europe, the EC have created the End-of-Life Vehicles (ELVs) Directive. Two of the most radical measures included in the Directive are to provide free takeback to last owners and to achieve targeted levels for the recycling and recovery of material by set dates. This paper aims to provide a basis for future research by evaluating the potential direction of the recovery industry. This is achieved firstly by assessing the origins of the directive and previous research surrounding the subject. The paper then describes the current recovery infrastructure and practices in the UK, highlighting all the stakeholders involved in the recovery industry. This paper also highlights the issues related to the provision of takeback and the attainment of targets through two stages, namely the implementation and management of takeback, and the use of new technology to achieve the recovery targets. The paper concludes by identifying key aims for future research to support the objectives of the implemented legislation and the financial stability of all stakeholders.
\end{abstract}

Keywords: end-of-life vehicles, manual disassembly, shredding, plastic recycling

\section{INTRODUCTION}

Unlike many products, the recovery of a vehicle through the reuse of its parts and the recycling of many of its constituent materials has existed since its inception. The structure of the car has always encouraged parts exchange and the technology of separating and recycling the valuable ferrous content is simple, reliable, and widespread. However, when the value of scrap steel has fallen, the loss of revenue to the recovery industry has usually forced many scrapyards to charge last owners for the disposal of their vehicle. This has previously caused an increase in vehicle abandonment, with the cost of disposal then falling on local government [1]. The recovery industry has also gained an image of unenvironmental conduct through the landfilling of the many hazardous substances within a vehicle [2]. The waste sent from the recovery industry to

*Corresponding author: Wolfson School of Mechanical and Manufacturing Engineering, Loughborough University, Loughborough, Leicestershire LE11 3TU, UK. email: c.j.edwards@ lboro.ac.uk landfill has been estimated to be between 20 and 30 per cent of each processed vehicle's weight, with a survey in 2000 estimating that from the 2.1 million vehicles recovered in the UK that year, approximately 403000 tonnes of waste in the form of automotive shredder residue (ASR) was landfilled [3]. The emergence of these three factors; abandonment, pollution, and waste has resulted in the creation by the European Commission of the End-ofLife Vehicles (ELVs) Directive which aims 'as a first priority, at the prevention of waste from vehicles and, in addition, at the reuse, recycling and other forms of recovery of end-of-life vehicles, and their components so as to reduce the disposal of waste, as well as at the improvement in the environmental performance of all of the economic operators involved in the life cycle of vehicles and especially the operators directly involved in the treatment of end-of-life vehicles' [4].

This was to be achieved through the implementation of several measures that include:

(a) the setting up of a system for the collection of ELVs by economic operators (producers, dismantlers, and shredders etc.); 
(b) the assurance that delivery to treatment facilities is at no cost to the last owner by 2007 (unless it does not contain 'the essential components of a vehicle' or contains waste which has been added);

(c) the establishment of standards for storage, treatment, de-pollution, and the regulation of authorised treatment facilities (ATFs);

(d) the recycling and recovery of 85 per cent (80 per cent recycling) of a vehicle's weight by 2006 , and 95 per cent (85 per cent recycling) by 2015.

The initial interpretation of the Directive was that the financial burden of implementing these measures would fall on the original manufacturers, making them liable for the disposal of their product and creating a link between themselves and end-oflife (EoL) operators, described by Deutz [5] as a 'value chain'. Vehicle manufacturers have been instigating environmental awareness for many years with the use of whole life cycle analysis [6] and 'design for' programmes [7] increasing the influence of EoL options on the design process. However, this producer responsibility is aimed at giving them a financial interest in recovery, encouraging them further to integrate EoL issues into design as well as incorporate recycled material into new vehicles.

As a result of the Directive, the old style 'scrapyards' now require authorized treatment facility (ATF) accreditation, guaranteeing the environmental treatment of vehicles in their care. They are also required to build new relationships with manufacturers to provide takeback and reassess old relationships with other actors in the recovery chain (as shown in Fig. 1) to achieve the recovery targets together. Through a review of the surrounding literature and discussion with many of the stakeholders involved, this paper considers the possible methods by which the 'value chain' can achieve the objectives of the Directive. Interviews have been conducted with manufacturers, ATFs, and shredder operators to build a picture of the current recovery industry and develop an understanding of its future direction, based on the two most radical measures included in the directive; free vehicle takeback and recycling/recovery targets. From this, future research activities have been highlighted that could help sustain a free takeback network and reduce landfilled waste.

\section{VEHICLE RECOVERY IN THE UK}

As the ELV Directive is implemented at a national level, each nation state will take responsibility for both the introduction and achievement of free takeback and the recovery targets. In Germany 10 per cent of the recovery rate is required through dismantling [8], while in the Netherlands a well-established flat-rate disposal levy is added to the price of new vehicles and invested in the recovery industry by Auto Recycling Netherlands (ARN) to ensure compliance for both free takeback and recovery targets [2]. The UK provides a good example of a moderate and common transposition of the Directive, where additional measures have not been attached, and takeback is the responsibility of each manufacturer. The legislation has been transposed into UK law through the EoL Vehicles Regulations 2003 [9] and the EoL Vehicles (Producer Responsibility) Regulations 2005 [10], and therefore the requirements for ATF status and de-pollution standards have been

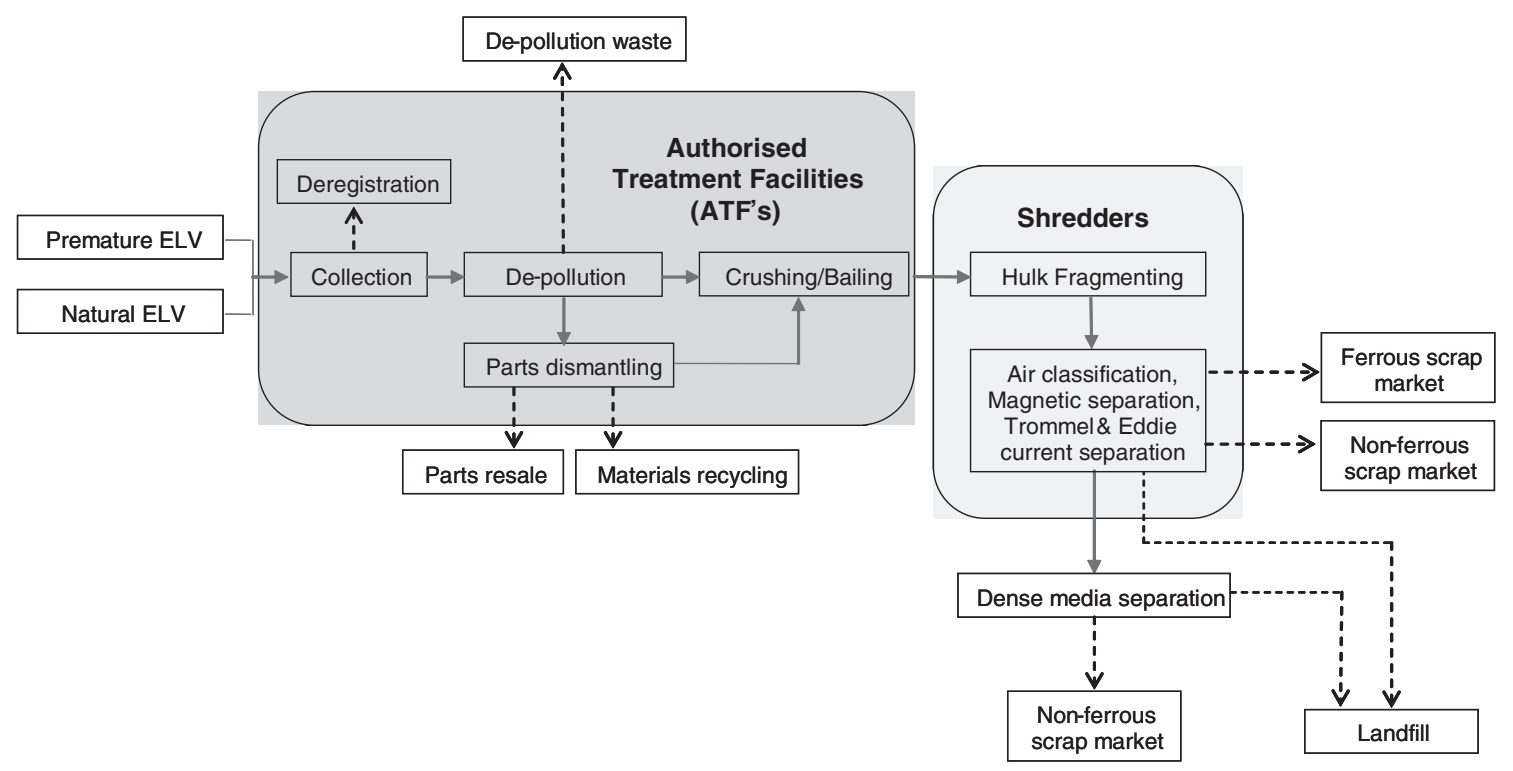

Fig. 1 The flow of the vehicle through EoL operations 


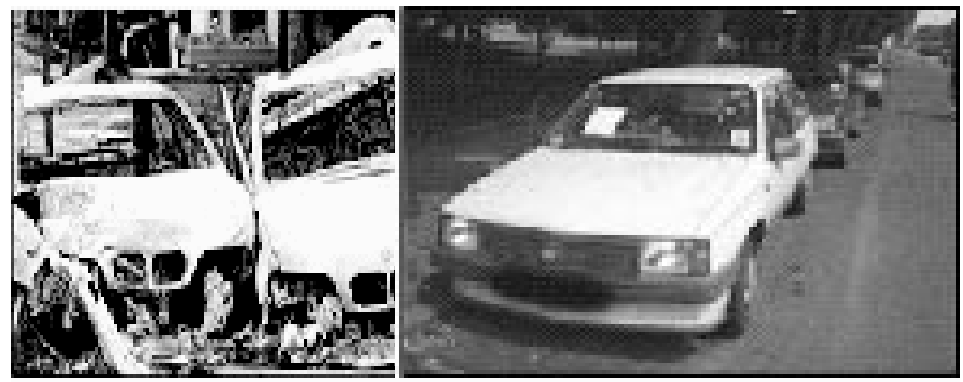

(a) (b)

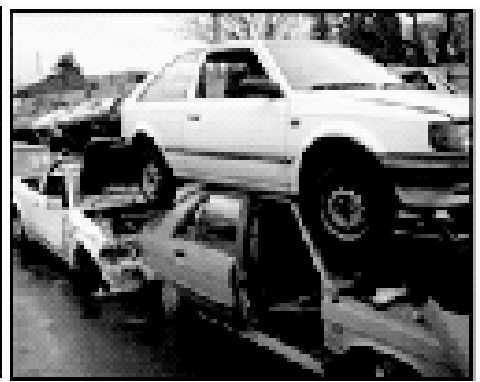

(c)

Fig. 2 ELV categories (a) premature fire, theft, vandalism, or accident ELVs; (b) abandoned ELVs that can fall under either; (c) natural ELVs

established. This section reviews the state of the recovery industry in the UK and describes the structure laid out in Fig. 1.

Traditionally, vehicles have arrived at scrap dealers because of their involvement in an accident or because they have come to the end of their useful lives (as shown in Fig. 2). Dependent on their age and make, these vehicles are then cannibalized for parts by the scrapyard before the remaining vehicle, normally called the 'hulk', is sold on to a shredder operator who recovers the ferrous content. However, there have been improvements in both the processes used and professionalism within an ATF as depollution and ATF status have become a requirement. Those who have achieved ATF status now de-register the vehicle, issue a certificate of destruction to the last owner, and de-pollute the vehicle, which requires the removal of the battery, fluids, tyres, and any other hazardous substances in a certified environment.

Although there is clearly an economic cost that comes with implementing these measures, many have made the successful transition to ATF status. This has been aided by the high value of scrap steel as depicted in Fig. 3 [11], which has brought increased profits from the sale of the hulk and, therefore, money to invest in the necessary equipment. However, the majority of stakeholders interviewed felt that the spare parts market was in decline, citing increased reliability, an expansion in onboard electronics, and frequent component design changes as the reasons for the downturn.

It is estimated that approximately 79 per cent of a vehicle's weight is recovered currently in the $\mathrm{UK}$, as illustrated in Fig. 4 [3], with around 10 per cent of this removed during de-pollution and dismantling at an ATF. However, there is no financial incentive to dismantle pure stream materials for recycling because of high labour costs and the lack of market for low quantities of non-metallic materials. Although the plastic content amounts to approximately 10 per cent of a vehicle's weight [3], the types of plastic used are varied,
Average quarterly shredded scrap steel price

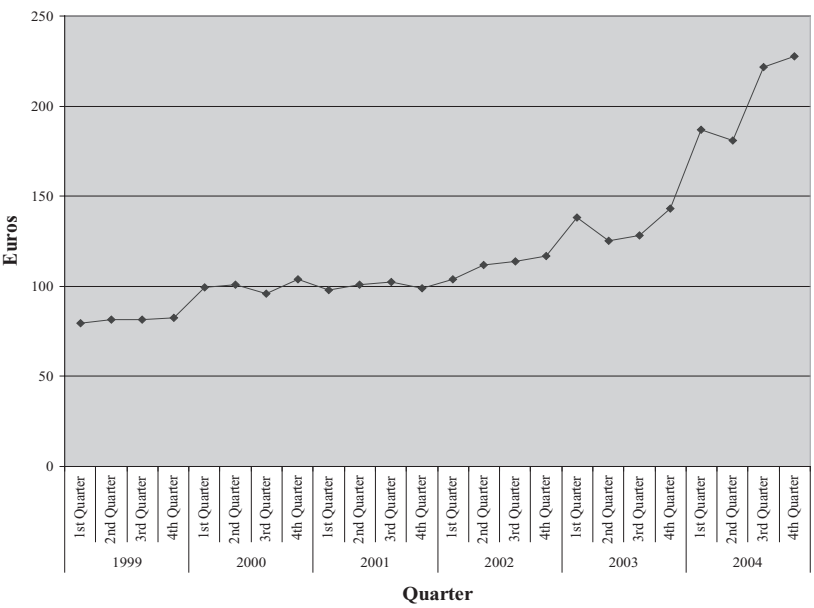

Fig. 3 The rise of shredded steel prices per tonne delivered (in Euros) between January 1998 and $2005[11]$

sometimes unidentifiable, and difficult to separate and clean.

When the vehicle hulk passes on to the shredder operator, the vehicle is shredded using a hammer mill and then, the ferrous metal (approximately 64 per cent) is removed using magnetic separation. The remaining fraction can then be separated further by using eddy current technology followed by dense media separation, which recovers a further 4 per cent of a vehicle's weight in non-ferrous metals. This leaves approximately 21 per cent to be sent to landfill as ASR.

\section{THE FUTURE DIRECTION OF THE UK RECOVERY INDUSTRY}

The way that the recovery targets in 2006 and the takeback networks in 2007 are measured and developed will have a major impact on the future prosperity of the recovery industry. In this section the future implementation of free takeback provision 


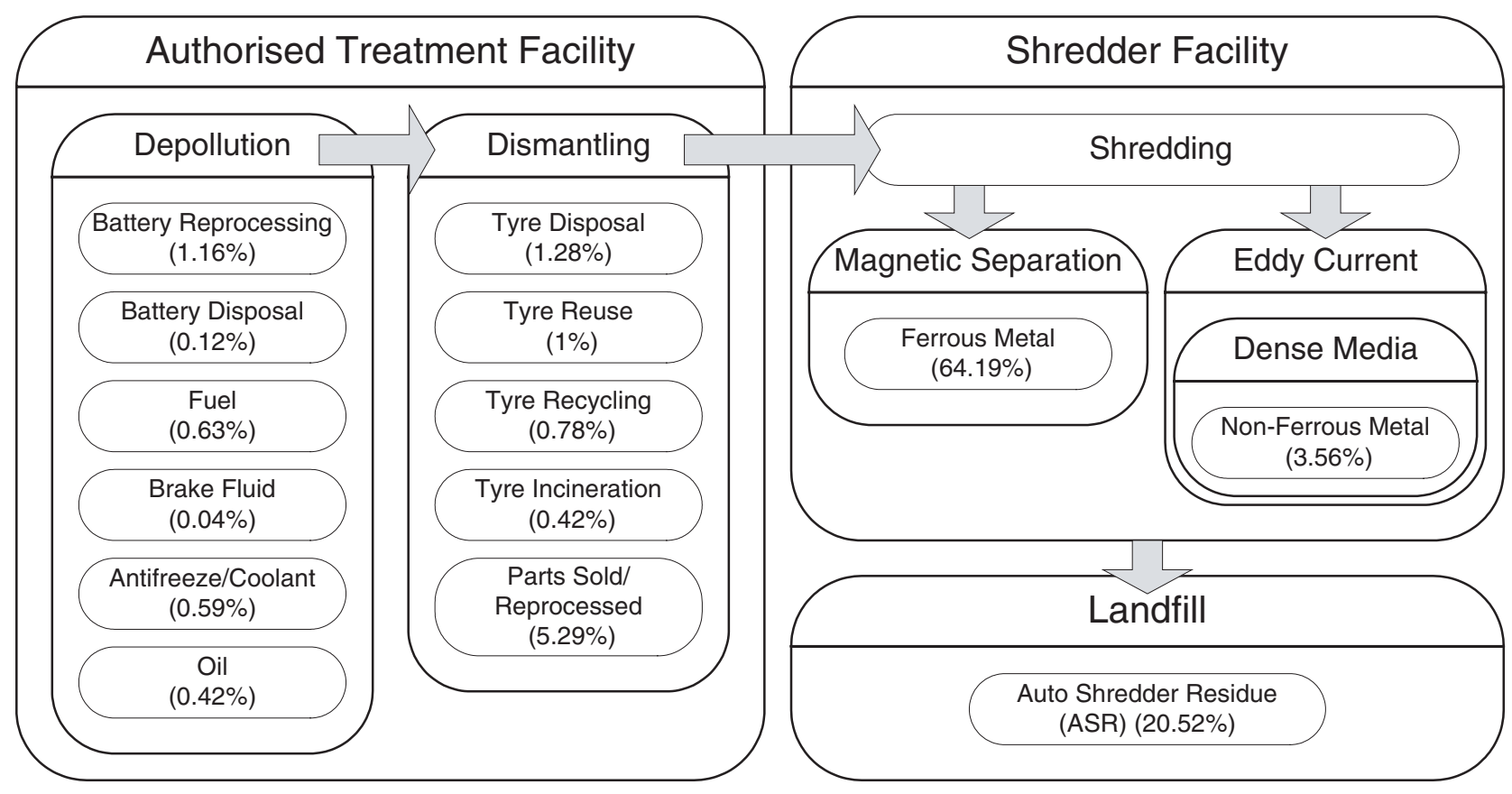

Fig. 4 The flow of material weights through the recovery chain [3]

and recovery targets will be discussed from a UK perspective based on knowledge gained from both literature and interviews with UK stakeholders.

\subsection{Free takeback}

Unlike the Netherlands, the UK is applying an 'own marque' approach to free takeback. This was developed after lobbying from the manufacturers, who felt that providing 'payment-per-car' recovery for all vehicles in the UK was too great a financial liability to appear on their balance sheets. The 'own marque' system adopted asks manufacturers to set up their own network of ATFs to deal with their vehicles. Due to the high value of scrap steel, many ATFs and shredder operators have been unwilling to give up any potential profit to vehicle manufacturers. This has led to the creation of a contractual agreement referred to by many stakeholders as a 'zero cost' contract. These contracts, as the name implies, see no monetary value exchanged between the automotive and recovery sectors. This free-market approach provides a takeback network that gives independence to the recovery chain at a time of high profit, with the manufacturers contributing to the promotion of the network. However, because of the suggested decline in the spare parts market, and with the cost of landfill set to increase from $£ 18$ per tonne to a medium-to-long-term rate of $£ 35$ per tonne, these factors are expected to impact on the profitability of ATFs. From the advent of 'zero cost' contracts and the financial barriers that the recovery industry faces, the following summations can be made.

1. 'Zero cost' contracts do not provide a direct financial incentive for manufacturers to increase recovery through design. One of the aims of the Directive was to provide producer responsibility so that vehicle manufacturers would have a financial interest in the recovery of their own vehicles. This would provide an incentive to reduce waste through the redesign of their vehicles, therefore promoting reuse and recycling not as an environmental need but as an economic necessity. Although the ELV regulations include fines for non-compliance, the use of zero-cost contracts provides it without any cost to the manufacturer.

2. A free-market system still leaves the recovery industry susceptible to market fluctuations. A drop in the value of scrap steel combined with an increase in landfill and de-pollution costs, would reduce the profitability of both ATFs and shredder operators. This financial burden would fall wholly on the recovery industry, with the manufacturers not obliged to give financial assistance unless it prevents their recovery network from providing free takeback, therefore incurring a fine for non-compliance.

\subsection{Recovery targets}

To meet the recovery targets for 2006 and 2015, the UK industry must recover an extra 7 per cent 
and 17 per cent respectively. As mentioned in section 2, dismantling more material at an ATF is not seen as viable by the stakeholders involved. The removal rates are too low and the amount of recyclable material collected too small to make manual dismantling profitable. Although 'design for disassembly' methods have been utilized for newer vehicles to make specific parts easier to remove, ATFs still report that this provides neither the removal time nor the quantity of material to make the removal of pure stream plastics worthwhile. This therefore puts much of the onus for recovery on post-shredder operations and ASR recovery methods.

One potential process is skin floatation, which attempts to separate thermoplastics and thermosets from the remaining ASR through their reaction to plasticizers [12]. After several stages of preparation, the material enters a 'quiet' tank where heavier engineering plastics sink and lighter olefin plastics and foams float. The light fraction can be separated further or recycled as thermoplastic olefins and thermoplastic elastomers (TPOs and TPEs) while the heavy fraction, composed of 25 per cent plastics (thermoplastic) and 75 per cent rubbers (thermoset), continues to a counter-current rinse tank. Plasticizers are then added to the tank, which induces air bubbles on the surfaces of certain plastics and forces them to float. It has been found that, using the right sequence of plasticizers, ABS, Nylon, PC, and PP can be removed from the ASR with a purity of at least 92 per cent [12]. However, the widespread adoption of this technology has yet to be commercially realized and doubts remain over the required cleanliness of the plastics for the flotation process to take place.

Another possible method is the gasification of waste, which attempts to separate its combustible particles from large inert and metallic particles by heating the waste on an internally circulating fluidized bed to between 500 and $600^{\circ} \mathrm{C}$. This method has been commercialized successfully in Japan through the TwinRec system, which has processed more than 170000 tonnes of waste in the first three years of its existence [13]. It takes unsorted and uncleaned ASR and, through a combination of a gasifier and a cyclone combustion chamber, separates the remaining ferrous and non-ferrous material, while creating energy through a boiler and construction granulate from the remaining slag. The manufacturers claim that from the 20 per cent of vehicle waste they receive, they are able to recover another 2.5 per cent of the metallic content, 5.5 per cent through recycling as construction materials, 10 per cent through energy recovery, and 1 per cent from metal salts, leaving 1 per cent of the vehicle's weight for landfill.
From the lack of financial incentive to remove more during disassembly and the new technologies available for post-shredder recovery, the following summations can be made.

1. The achievement of the recovery targets is dependent on post-shredder separation. Because the financial burden will fall on the recovery industry, as discussed in the previous section, they now must find the most economic method of achieving the recovery targets. Manual dismantling is not seen as economically viable by the recovery industry and they see no market to create a financial incentive, therefore, post-shredder separation provides the most economic means of reaching the targets.

2. The technology does not exist to recover postshredder plastics for closed-loop recycling. Although the two technologies presented in this paper could eventually provide compliance, the purity of the materials separated precludes their use in the same application. Cascade recycling, where they are utilized in lower specification applications, is a potential solution. However, several stakeholders reported that there are currently not enough of these applications to provide a market for the quantity of mixed plastic that could be recovered.

\section{CONCLUSION}

The review of literature and interviews with many of the stakeholders involved has signalled several key indicators to the future direction of the vehicle recovery industry. In terms of free takeback, manufacturers are beginning to establish networks in the UK through several 'zero-cost' contracts. The added costs of de-pollution created by the legislation have been absorbed by the extra revenue created by the high value of scrap steel. However, there is no direct financial aid from the manufacturers, which has left many ATFs as vulnerable to changing markets as they were before the Directive's inception. These ATFs require guidance to maximize their profits through the development of emerging markets. Although many stakeholders believe plastic removal is uneconomic, a market does exist for recycled polymers that remains unexploited by the automotive recovery industry. If detailed information could be gathered on a limited number of parts on specified vehicles along with the potential value of their material content, ATFs would have the ability to base dismantling decisions on real data.

The achievement of the Directive's recovery and recycling targets is less clear. There is some 
confidence within the recovery industry that the 85 per cent target will be met. The research in this paper indicates that the increase in recovery levels required for both 2006 and 2015 will come from post-shredder operations. Although many EU states have different methods of implementation, the recovery targets are the same across the continent and the responsibility of the manufacturers to help achieve them is clear. Future EU type approval regulation [14] will add to manufacturer responsibility by asking them to provide details of how their new vehicles will be recovered. It is therefore essential that the automotive industry is aware of the impact of their product on these processes so that they can be considered during the design process. This could not only aid material selection, but give the manufacturers an impression of the recoverability of their vehicles. Therefore, the authors' future research will focus on aiding ATFs with dismantling decisions through the use of cost models and assisting manufacturers with design decisions based on postshredder operations.

\section{REFERENCES}

1 House of Commons Environment, Food and Rural Affairs Committee. End-of-life vehicles directive and waste electrical and electronic equipment directive: Fourth report of session 2003-2004, 2004.

2 Zoboli, R., Barbiroli, G., Leoncini, R., Mazzanti, M., and Montresor, S. Regulation and innovation in the area of end-of-life vehicles. European Commission, 2000.

3 Kollamthodi, S., Hird, A. B., Elghali, L., Johnstone, K., Wayman, M., and McColl, V. Data required to monitor compliance with the End of Life vehicles directive. TRL Limited, www.defra.gov.uk/environment/waste/ topics/elvehicledir.htm, 2003.
4 European Commission. Directive 2000/53/EC of the European Parliament and of the Council of the 18th September 2000 on End-of-Life Vehicles. European Commission, 2000.

5 Deutz, P. Environmental regulation as a driver for change in the value chain: EU End of Life Vehicle Directive and its impact on the automotive value chain. Supply chains and total product systems: a holistic perspective, 2004.

6 Resetar, S., Camm, F., and Drezner, J. Environmental management in design: lessons from Volvo and Hewlett-Packard for the Department of Defence. National Defence Research Institute, 1998.

7 Coppens, C., Le Coq, M., Millet, D., and Michaud, P. Evaluating and improving the recovery aptitude of an automobile function: the PSA approach. Int. J. Veh. Des., 2002, 29(4); 307-316.

8 Perchard, D. Transposition of the ELV Directive in other EU member states. Perchards, 2004.

9 UK Government. Statutory instrument 2003 No. 2635: the end-of-life vehicles regulations 2003. UK Government, 2003.

10 UK Government. Statutory instrument 2005 No. 263: the end-of-life vehicles (producer responsibility) regulations 2005. UK Government, 2005.

11 Eurofer. The European Confederation of Iron and Steel Industries, Scrap price index. www.eurofer.org/ statistics/scrap.html, 2005, January 2005.

12 Winslow, G. R., Kobler, R. W., Duranceau, C., Caron, J. D., and Lui, S. Recovery of selected engineering plastics from automotive shredder residue using skin flotation technology. SAE paper 1999-01-0663, 1999.

13 Selinger, A., Steiner, C., and Shin, K. TwinRec bridging the gap of car recycling in Europe. International automobile recycling congress, Geneva, 2003.

14 European Commission. Proposal for a Directive of the European Parliament and of the Council on the type-approval of motor vehicles with regard to their re-useability, recyclability and recoverability and amending Council Directive 70/156/EEC. European Commission, 2004. 